\title{
Selection of Powder or Wire Feedstock Material for the Laser Cladding of Inconel ${ }^{\circledR} 625$
}

\author{
J.C. Heigel ${ }^{\mathrm{a}, *}$, M.F. Gouge ${ }^{\mathrm{a}}$, P. Michaleris ${ }^{\mathrm{a}, 1}$, T.A. Palmer ${ }^{\mathrm{b}}$ \\ ${ }^{a}$ Department of Mechanical and Nuclear Engineering, The Pennsylvania State University \\ ${ }^{b}$ Applied Research Laboratory at The Pennsylvania State University
}

\begin{abstract}
The selection of the feedstock material form significantly affects the temperature and resulting distortion generated during laser cladding. An experimental investigation is undertaken to characterize the differences in temperature and deformation histories resulting from laser cladding using powder and wire. While both feedstock produce good quality clads, the powder clad is nearly twice as thick as the wire clad. In situ measurements show that the selection of a powder feedstock results in higher temperatures and greater deformation. However, characterization of the final distortion shows that each clad twists the substrate by nearly the same amount. Thermo-mechanical modeling of the process shows that the disparity in laser absorption efficiency is responsible for the variation in temperature between the powder and wire. Simulations of a multi-layer deposition show that although a single wire layer generates lower temperatures and less deformation than a single powder layer, the wire clad will actually produce greater total deformation because two layers
\end{abstract}

\footnotetext{
* Corresponding author

Email address: jarred.heigel@gmail.com (J.C. Heigel)

${ }^{1}$ President of Pan Computing LLC.
} 
are required to achieve the same thickness as the powder clad.

Keywords: Laser cladding; Inconel 625; Powder and wire feedstock; In situ measurements; FE simulation

\section{Introduction}

Laser cladding is an additive manufacturing process in which a melt pool is created and traversed across a metallic substrate and into which either a powder or wire feedstock is injected to build-up thin layers. These clad layers

5 are added to improve the properties and performance of a part, or to replace material degraded during service. Toyserkani et al. (2005) found that when compared to arc welding based processes, laser cladding produces lower levels of dilution and distortion. Even with laser cladding, the large thermal gradients and contraction of molten material generate residual stresses and distortion in

10 the substrate that cannot be completely avoided.

Several studies have been undertaken to investigate the stresses and distortion generated during laser cladding with powder. For instance, Grum and Žnidaršič (2004) used $\mathrm{SiC}$, Stellite ${ }^{\circledR} 6$ and Stellundum 481 powders to clad low carbon structural steel in order to improve its surface properties. In situ

15 measurements of the process using strain gauges and post process measurements of the residual stress revealed that the distortion and stress were affected by the clad pattern and the powder material. Ocelík et al. (2009) clad steel and stainless steel substrates using NanoSteel, Eutroloy ${ }^{\circledR}$ 16012, and MicroMelt ${ }^{\circledR}$ 23 powders and measured the strain during the clad process using digital 20 image correlation techniques. Their results indicated that substantial strain 
was generated due to local heating as the laser passed over the measurement point and that by increasing the laser speed, which decreased the linear heat input, this strain could be decreased. Heigel et al. (2015a) performed an investigation into the impact of processing conditions on the magnitude and

25 mode of distortion generated during laser cladding of Inconel ${ }^{\circledR} 625$ powder onto substrates of the same material. Thermocouples and a laser displacement sensor were used to measure the temperature and deflection of the substrates in situ. They found that the long processing times enabled a significant amount of heat transfer through convection and radiation, which in turn decreased the so distortion. In fact, follow up work by Heigel et al. (2014) demonstrated that the forced convection generated by argon jets during laser cladding and laser based additive manufacturing must be taken into account to accurately model the energy balance in finite element (FE) models. Furthermore, Gouge et al. (2015) demonstrated that when developing thermal FE models of the cladding 35 process, the implementation of measurement-based forced convection models leads to more accurate results compared to those obtained when incorporating forced convection models from the literature, which depend on the Reynold's number of the impinging gas and the nozzle diameter to surface distance ratio. Plati et al. (2006) measured the temperature and distortion of a stainless steel 40 substrate clad with a nickel based metal matrix composite (MMC) powder. They noted that the deposition of a relatively thin layer of powder had little impact on the distortion of the substrate since the majority of the laser energy is absorbed by the substrate, and only a portion of the energy is absorbed by 
the powder before it reaches the melt pool.

45 The ability of coaxially fed powder to absorb energy from the laser beam before it reaches the melt pool has been the focus of other studies. Lin (1999) measured the temperature distribution of a stainless steel powder stream flowing coaxially through a $1 \mathrm{~kW}$ laser beam, showing that the powder can melt in-flight before it reaches the melt pool. However, its ability to do so is dependent upon 50 the laser power and velocities of the particles and the argon gas carrier jet. Huang et al. (2005) simulated the interaction between a Gaussian laser beam and a cobalt alloy powder stream. Their results demonstrate that the angular positioning of the powder stream relative to the laser beam had a significant impact on the temperature distribution of the powder as it strikes the surface and on the intensity profile of the beam at the surface. Partes (2009) found it necessary to include the in-flight melting of a cobalt alloy powder to accurately model the capture efficiency. These studies illustrate that the absorption of the powder in-flight can have measurable effects on the process temperatures during laser cladding.

Wire is appealing as an alternative feedstock form to powder because, as Toyserkani et al. (2005) discussed, it is usually less expensive and results in less waste. It can produce superior clad surfaces, reduce cost and contamination, and be used in a variety of cladding positions that allow for access to a wider range of geometries. However, cladding with wire poses different challenges than ${ }_{65}$ cladding with powder. For instance, accurate placement of the wire with respect to the melt pool is critical because the wire must be fed directly into the melt 
pool so that it is completely melted by the heat of the melt pool. Kim and Peng (2000b) demonstrated that if the wire is not plunged into the melt pool, it can melt before reaching the melt pool surface and form drops which fall onto the 70 surface and degrade the clad quality.

Regardless of the feedstock, it has been shown that the melt pool depth is dependent on the amount of energy that reaches the substrate. For example, Kim and Peng (2000a) found that when laser cladding single tracks of Inconel ${ }^{\circledR}$ 600 wire onto Inconel ${ }^{\circledR} 690$ plates with a $220 \mathrm{~W}$ laser, the melt pool depth 75 decreased from $0.5 \mathrm{~mm}$ to $0.25 \mathrm{~mm}$ when the travel speed was increased from $1.5 \mathrm{~mm} / \mathrm{s}$ to $2.5 \mathrm{~mm} / \mathrm{s}$. Toyserkani et al. (2005) found that in general, dilution and melt pool depth are directly related to laser power and inversely related to travel speed, and therefore directly related to the linear heat input. The melt pool depth can also be impacted by changing the mass feed rate of the powder or so wire feedstock. Toyserkani et al. (2003) found that while keeping the power and travel speed constant and increasing the powder feed rate, the temperature of the substrate and the melt pool depth decreased. This behavior was attributed to the greater amount of absorbed laser energy in the powder, which in turn decreased the amount of laser energy that could be absorbed by the substrate.

85 In fact, when the mass feed rate became high enough, the melt pool did not penetrate deep enough to produce sufficient substrate melting, thus drastically decreasing the bond strength between the clad and substrate.

While much of this previous work has focused on the impact of changing processing conditions on the resulting laser clad properties, there is little 
insight governing the selection of powder or wire feedstock forms. In order to avoid the impact of material selection and to replicate the conditions typically found in repair and refurbishment activities, matching Inconel ${ }^{\circledR} 625$ feedstock and substrate are used to evaluate the impact of different feedstock forms. The impact of feedstock form, either powder or wire, on the temperature 95 and distortion histories are measured in situ using thermocouples and a laser displacement sensor, respectively. Afterwards, the final distortion of each plate is measured using a coordinate measurement machine (CMM) and the clad quality and melt pool dilution are assessed. These in situ and post process measurements reveal disparities in the temperature, distortion, and clad thickness, where cladding with powder results in higher temperatures, more distortion, and a thicker clad layer. Finite element (FE) analysis is then used to estimate the net laser absorption efficiency of each feedstock that would lead to the difference in temperature. Finally, because the measurements reveal that the wire clad layer is half as thick as the powder clad layer, multi-layer clad 105 simulations are performed to determine the total distortion resulting from each feedstock to produce a clad of the same thickness.

\section{Experimental Procedure}

Inconel ${ }^{\circledR} 625$ plates, which are $152.4 \mathrm{~mm}$ long, $76.2 \mathrm{~mm}$ wide, and $6.35 \mathrm{~mm}$ thick, are clamped into a fixture on one end to allow the free end to deflect and the substrate temperature and deflection to be measured during the cladding process (Figure 1). This setup allows the temperature and distortion histories to 
be measured while allowing the same experimental conditions to be maintained with both feedstock forms. The in situ distortion measurements are taken with a Keyance LK-031 Laser Displacement Sensor (LDS), which has a resolution and accuracy of $1 \mu \mathrm{m}$, and the temperature history during the build is measured at various locations using Omega GG-K-30 type K thermocouples, which have a measurement uncertainty equal to the larger value of $2.2^{\circ} \mathrm{C}$ or $0.75 \%$. The clad is performed using a YLR-12000 IPG Photonics ${ }^{\circledR}$ fiber laser. The beam is delivered by a $200 \mu \mathrm{m}$ fiber into a $200 \mathrm{~mm}$ collimator and a $200 \mathrm{~mm}$ focal lens, ${ }_{120}$ resulting in a beam with a diameter of approximately $4 \mathrm{~mm}$ on the surface of the part to create the melt pool. A Primes ${ }^{\circledR}$ beam focus monitor is used to verify the Gaussian profile of the beam. A Precitec YC50 clad head, nominally positioned $10 \mathrm{~mm}$ above the part surface, delivers powder to the melt pool and shields the laser optics using two separate argon gas flows of $9 \mathrm{~L} / \mathrm{min}$. The ${ }_{125}$ head is tilted $5^{\circ}$ to minimize the possibility of the beam reflection damaging the optics. Greater detail on the cladding system and measurement setup can be found in Heigel et al. (2015a). 


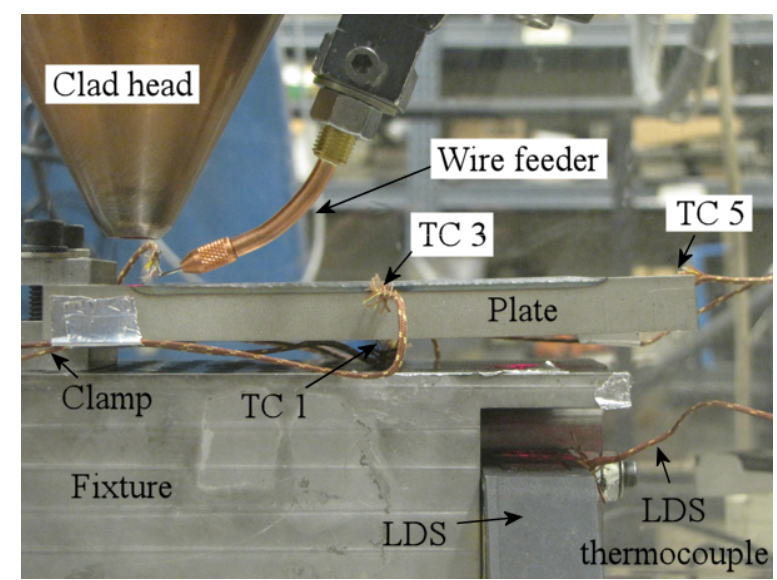

Figure 1: The experiment setup.

The schematic diagrams in Figure 2 show the locations of the LDS target point and the thermocouples. Two thermocouples are attached to the bottom of 130 the substrate, with one (TC 1) located at the center point and the other (TC 2) located approximately $4 \mathrm{~mm}$ from the edge of the plate and half way along the length of the plate. Two additional thermocouples are placed on the side walls of the substrate as near the top surface as possible, with one (TC 3) located half way along the side face coinciding with the first pass while the other (TC 4) is located at the mid point of the side face coinciding with the last pass. One thermocouple (TC 5) is located on the face of the free end of the plate, along its midpoint as near the top surface as possible. The final thermocouple (TC 6) is located at the top surface, near the clamp. The ambient temperature of the build volume is measured using an additional thermocouple that is not attached ${ }_{140}$ to the substrate. 


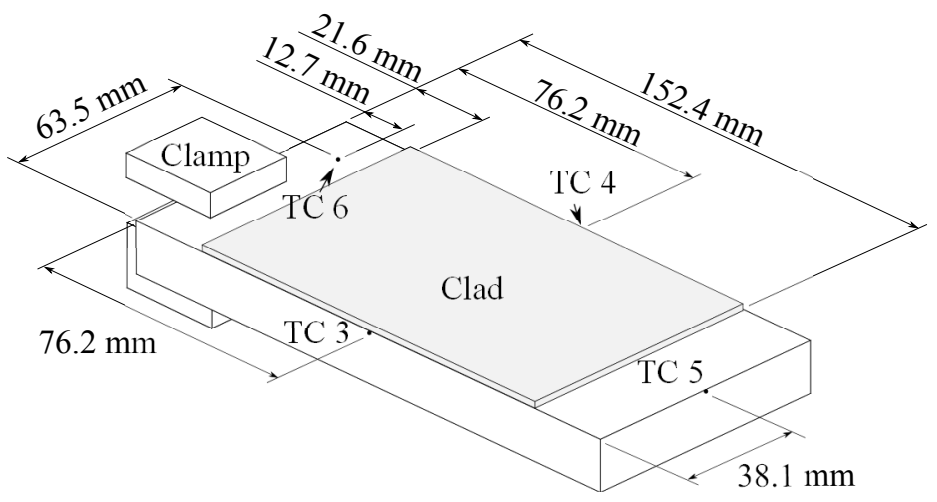

(a) The top surface of the plate

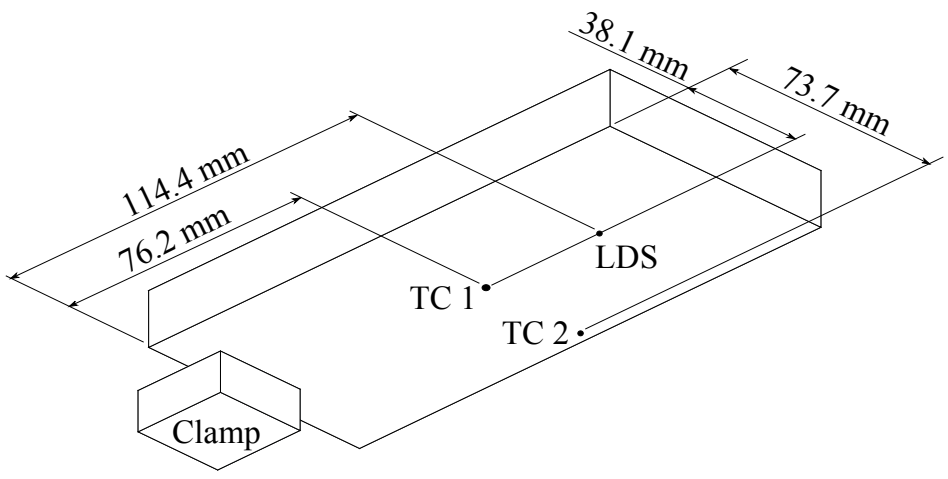

(b) The bottom surface of the plate

Figure 2: Schematics of a) the top and b) the bottom surfaces of the plate showing the measurement locations.

The process conditions used in this study are presented in Table 1. Each of the 36 passes, which are $109 \mathrm{~mm}$ long, are deposited in the same direction along the longitudinal axis of the plate. In each case, the nominal laser power $(P)$ is $2.5 \mathrm{~kW}$, the travel speed $(v)$ is $10.6 \mathrm{~mm} / \mathrm{s}$, and the hatch spacing is $2.032 \mathrm{~mm}$.

145 The nominal linear heat input is related to the nominal laser power and travel speed through the following relationship:

$$
\text { linear heat }=\frac{P}{v}
$$


Inconel ${ }^{\circledR} 625$ powder sieved to a particle size distribution between $44 \mu \mathrm{m}$ and $149 \mu \mathrm{m}(-100 /+325$ sieve size $)$ is injected at a rate of $19 \mathrm{~g} / \mathrm{min}$ into the melt pool to produce the powder clad. The powder stream is focused at the surface of the part. Only a percentage of this material is added to the melt pool, as described by the capture efficiency:

$$
\text { capture efficiency }=\frac{m_{\mathrm{f}}-m_{\mathrm{i}}}{f \frac{l p}{v}}
$$

where $m_{\mathrm{i}}$ and $m_{\mathrm{f}}$ are the weights of the plate before and after the cladding process, $f$ is the mass feed rate, $l$ is the pass length, $p$ is the number of passes, and $v$ is the laser velocity. To produce the wire clad, Inconel ${ }^{\circledR} 625$ wire with 155 a diameter of $0.76 \mathrm{~mm}$ is injected while leading the melt pool at a rate of $1.78 \mathrm{~m} / \mathrm{min}$ into the melt pool, which equates to a mass rate of $6.81 \mathrm{~g} / \mathrm{min}$. All of the wire material is consumed in the melt pool as confirmed by the postprocess mass measurement. The wire feeder delivers the wire to the front of the melt pool at an angle of $20^{\circ}$ from the substrate. Both argon jets, without the inclusion of powder, are used to minimize the deviation in convective cooling between the two processes. The mass feedrates used in this study have been identified to produce fully dense clads at the chosen laser power, travel speed, and hatch spacing. 
Table 1: The process conditions used in this study.

\begin{tabular}{lcc}
\hline Inconel ${ }^{\circledR}$ 625 feedstock & Powder & Wire \\
\hline Nominal laser power $(\mathrm{kW})$ & 2.5 & 2.5 \\
Travel speed $(\mathrm{mm} / \mathrm{s})$ & 10.6 & 10.6 \\
Nominal linear heat input $(\mathrm{J} / \mathrm{mm})$ & 236 & 236 \\
Nominal mass feed rate $(\mathrm{g} / \mathrm{min})$ & 19.0 & 6.81 \\
Number of passes & 36 & 36 \\
Hatch spacing $(\mathrm{mm})$ & 2.03 & 2.03 \\
Pass length $(\mathrm{mm})$ & 109.2 & 109.2 \\
Clad thickness $(\mathrm{mm})$ & 1.42 & 0.74 \\
Capture efficiency $(\%)$ & 72 & 100 \\
\hline
\end{tabular}

The $10 \mathrm{~mm}$ offset distance between the bottom of the clad head and the part must be maintained in order to ensure the intended laser beam diameter, powder concentration, and injection of the wire into the melt pool. Because the cantilevered setup in this study allows the plate to freely deflect, the vertical positioning of the clad head must be changed to maintain the offset and resulting clad quality. As each track is deposited, the head is moved upward to follow the anticipated deflection of the plate resulting from the contraction of the molten material. The deflection measured by Heigel et al. (2015a) resulting from a powder clad using similar processing conditions to this current work is used to anticipate the deflection of each track, as illustrated in Figure 3. Although this prediction is based on a powder clad, the deviation between the wire and powder 175 clad is not significant enough to impact the wire placement and clad quality.

This strategy produces clads with the acceptable surfaces shown in Figure 4. 


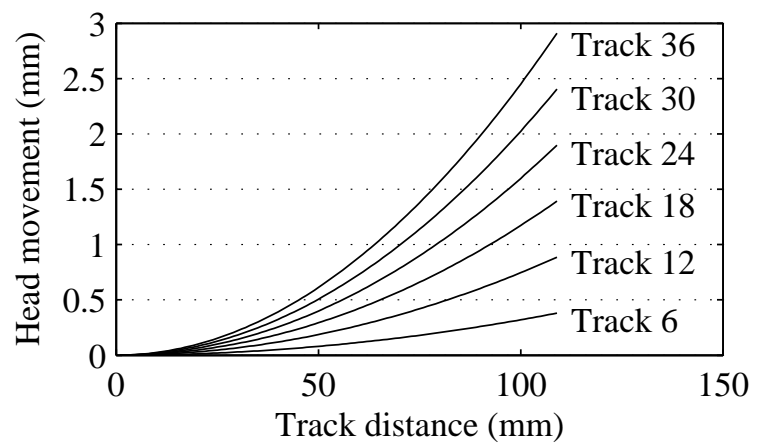

Figure 3: The vertical correction used for each track to minimize deviation of the head offset.

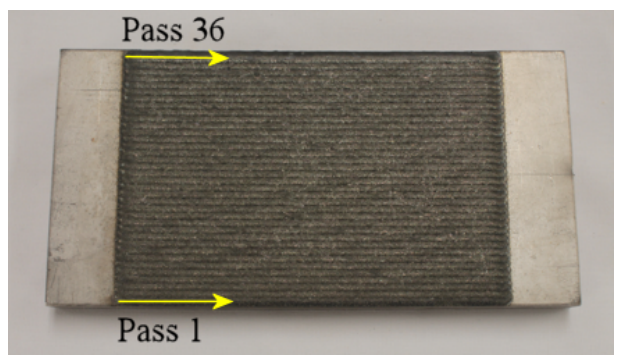

(a) Powder clad

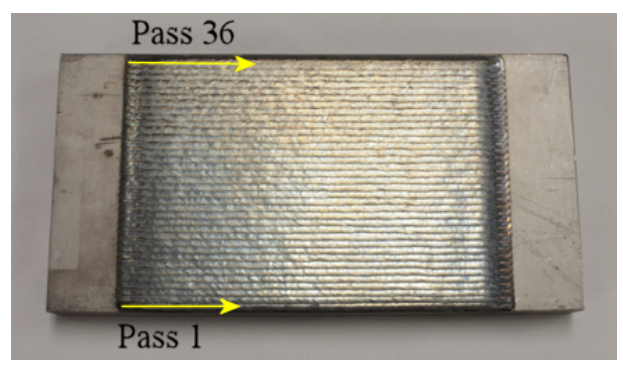

(b) Wire clad

Figure 4: Images of the clad resulting from each feedstock.

After cladding the final distorted shape of each plate is characterized using the same method described by Heigel et al. (2015a). Measurements are taken before and after the deposition at 9 locations using a CMM on the bottom

surface of the substrate and the difference between these measurements is used 
to determine the distorted profile. After the CMM measurements, each plate is sectioned to investigate the clad quality and the melt pool dilution. Figure 5 shows that sections are cut from each plate then mounted and polished so images can be taken to measure the maximum depth of the melt pool, $b$. The clad

185 height, $h$, is determined by measuring the total distance from the bottom of the substrate to the top of the clad and subtracting the original substrate thickness. From this, the geometrical dilution of the melt pool is calculated using the definition presented by Toyserkani et al. (2003):

$$
\text { dilution }=\frac{b}{h+b}
$$

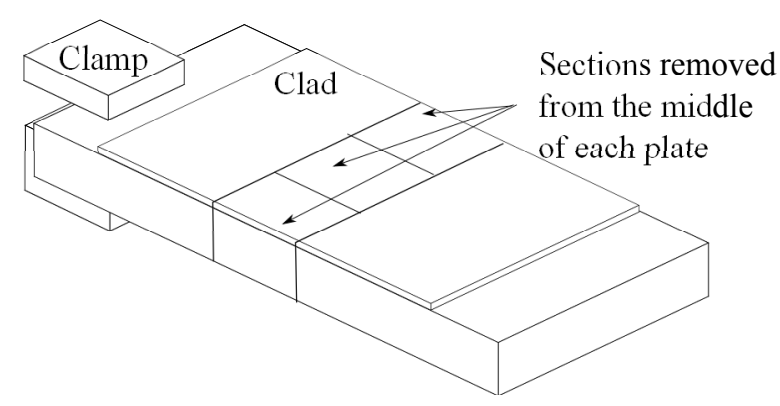

Figure 5: Diagram of the locations where the sections are removed from each plate.

\section{Finite Element Analysis}

FE analysis provides additional insight into the cladding process. A thermomechanical model allows the impact from laser absorption and multi-layer clads to be investigated. The thermo-mechanical model used in this study has been developed and validated for laser cladding of Inconel ${ }^{\circledR} 625$ plates by Gouge 
et al. (2015). The same model has been developed and validated by Heigel et al.

195 (2014) for building slender Ti-6Al-4V structures. Before these works, Denlinger et al. (2014) first developed and validated the model for a simple electron beam deposition with wire. The robustness of the model was then demonstrated by Denlinger et al. (2015) by modeling the deposition of a very large part, which required thousands of passes. Although greater detail of the model can be found in these prior works, a brief description of the thermal and mechanical models, as well as the numerical implementation is presented in the following sections.

\subsection{Thermal Model}

A three dimensional transient thermal analysis is used to investigate the temperature history of the powder and wire clads. This model does not in205 clude the effect of fluid flow within the melt pool because it is used for the analysis of far field effects such as the thermal history and distortion within the substrate. An earlier study by Lawrence and Michaleris (2011) in welding have shown that unless keyholing occurs in the melt pool, neglecting the fluid flow effects will have negligible effects on the distortion. FE analysis is beneficial for investigating process fundamentals because variables that are inter-connected during processing can be decoupled, allowing their effects to be studied. The thermal analysis is dependent upon the density $(\rho)$, specific heat $\left(C_{\mathrm{p}}\right)$, and thermal conductivity $(k)$ of the material. Except for the density, which is 8.44 $\mathrm{g} / \mathrm{cm}^{3}$, these properties are temperature dependent and are presented in Table 2 
${ }_{215}$ (Metals (2006)). The governing heat transfer energy balance is:

$$
\rho C_{\mathrm{p}} \frac{d T}{d t}=-\nabla \cdot \mathbf{q}(\mathbf{r}, t)+Q(\mathbf{r}, t)
$$

where the variables $T, t, Q$, and $r$ are the temperature, time, heat source, and relative reference coordinate. The heat flux vector, $\mathbf{q}$, is calculated as:

$$
\mathbf{q}=-k \nabla T
$$

Table 2: Temperature dependent thermal properties of Inconel ${ }^{\circledR} 625$ from Metals (2006).

\begin{tabular}{ccc}
\hline$T\left({ }^{\circ} \mathrm{C}\right)$ & $k\left(\mathrm{~W} / \mathrm{m} /{ }^{\circ} \mathrm{C}\right)$ & $C_{p}\left(\mathrm{~J} / \mathrm{kg} /{ }^{\circ} \mathrm{C}\right)$ \\
\hline 21 & 9.8 & 410 \\
93 & 10.8 & 427 \\
204 & 12.5 & 456 \\
316 & 14.1 & 481 \\
427 & 15.7 & 511 \\
538 & 17.5 & 536 \\
649 & 19.0 & 565 \\
760 & 20.8 & 590 \\
871 & 22.8 & 620 \\
982 & 25.2 & 645
\end{tabular}

Heat loss occurs on all surfaces of the model through radiation, $q_{\mathrm{rad}}$, and convection, $q_{\text {conv }}$. The Stefan-Boltzman law defines radiation:

$$
q_{\mathrm{rad}}=\varepsilon \beta\left(T_{s}^{4}-T_{\infty}^{4}\right)
$$

${ }_{220}$ where $\varepsilon$ is the emissivity of the material, $\beta$ is the Stefan-Boltzman constant, $T_{\mathrm{s}}$ is the surface temperature, and $T_{\infty}$ is the measured ambient temperature. 
Emissivity is assumed to be independent of temperature and set to a value of 0.43 as found by Omega Engineering Inc. (1998). Heat loss through convection is defined by the relationship below:

$$
q_{\mathrm{conv}}=h\left(T_{\mathrm{s}}-T_{\infty}\right)
$$

225 where the coefficient of convection, $h$, is based on measurements performed by Heigel et al. (2015b) of the forced convection generated by the argon jets emitted by the deposition head, and will be discussed further in Section 3.3.

\subsection{Mechanical Model}

A three dimensional quasi-static mechanical analysis is performed using the thermal simulation results as an input. There is a weak coupling of the thermal and mechanical models, where the mechanical model is dependent on the thermal results, but there is no feedback of the mechanical results to the thermal model. The mechanical analysis is dependent upon the elastic modulus $(E)$, poisson's ratio $(\nu)$, coefficient of thermal expansion $(\alpha)$, yield strength $\left(\sigma_{\mathrm{y}}\right)$, and ultimate strength $\left(\sigma_{\mathrm{u}}\right)$, which is measured at a strain of $\epsilon_{\mathrm{u}}$. In the substrate, each of these properties is temperature dependent, extracted from Metals (2006), and presented in Table 3. Temperature independent yield strength (634 MPa) and ultimate strength (931 MPa), measured by Keicher et al. (1997) at a strain of 0.38 , are used for the clad layer. The stress equilibrium is governed by:

$$
\nabla \cdot \boldsymbol{\sigma}=0
$$




$$
\begin{gathered}
\sigma=\mathrm{C}_{\mathrm{e}} \\
\boldsymbol{\epsilon}=\boldsymbol{\epsilon}_{\mathrm{e}}+\boldsymbol{\epsilon}_{\mathrm{p}}+\boldsymbol{\epsilon}_{\mathrm{T}}
\end{gathered}
$$

where $C$ is the fourth order material stiffness tensor and the variables $\boldsymbol{\epsilon}, \boldsymbol{\epsilon}_{\mathrm{e}}, \boldsymbol{\epsilon}_{\mathrm{p}}$, and $\boldsymbol{\epsilon}_{\mathrm{T}}$ are the total, elastic, plastic, and thermal strains.

Table 3: Temperature dependent mechanical properties of Inconel ${ }^{\circledR} 625$ from Metals (2006).

\begin{tabular}{ccccccc}
\hline$T\left({ }^{\circ} \mathrm{C}\right)$ & $E(\mathrm{GPa})$ & $\nu$ & $\alpha\left(\mu \mathrm{m} / \mathrm{m} /{ }^{\circ} \mathrm{C}\right)$ & $\sigma_{\mathrm{y}}(\mathrm{MPa})$ & $\sigma_{\mathrm{u}}(\mathrm{MPa})$ & $\epsilon_{\mathrm{u}}$ \\
\hline 21 & 208 & 0.278 & 12.8 & 479 & 965 & 0.54 \\
93 & 204 & 0.280 & 12.8 & 466 & 946 & 0.48 \\
204 & 198 & 0.286 & 13.1 & 440 & 906 & 0.47 \\
316 & 192 & 0.290 & 13.3 & 426 & 896 & 0.46 \\
427 & 186 & 0.295 & 13.7 & 419 & 914 & 0.49 \\
538 & 179 & 0.305 & 14.0 & 418 & 914 & 0.48 \\
649 & 170 & 0.321 & 14.8 & 425 & 825 & 0.33 \\
760 & 161 & 0.340 & 15.3 & 421 & 543 & 0.46 \\
871 & 148 & 0.340 & 15.8 & 279 & 279 & 1.25 \\
927 & 148 & 0.340 & 16.2 & 130 & 130 & 1.50 \\
\hline
\end{tabular}

\subsection{Numerical Implementation}

The 3D mesh used for both the thermal and mechanical analysis of the powder clad is presented in Figure 6. The mesh allows for the simulation of two clad layers and consists of a total of 115,474 nodes and 104,734 hex 8 elements. The aluminum clamp is included to capture the heat transferred from the substrate during deposition. Each clad layer is modeled as a single layer of elements, with a height equal to the deposition thickness reported in Table 1. The width and length of each element in the clad is equal to half 
of the laser radius $(1.016 \mathrm{~mm})$. The convergence study performed by Gouge et al. (2015) on a similar geometry found this to be a sufficiently fine mesh. Mechanical constraints are applied to the substrate at the clamp so it is free to deform like the cantilevered experiments. Comparisons are made between the model and experiments by extracting data from the nodes that correspond to the thermocouple and LDS measurement locations, as indicated in Figure 6. The mesh used for the wire analysis is identical except for the thickness of each clad layer which is equal to the measured thickness of $0.74 \mathrm{~mm}$.

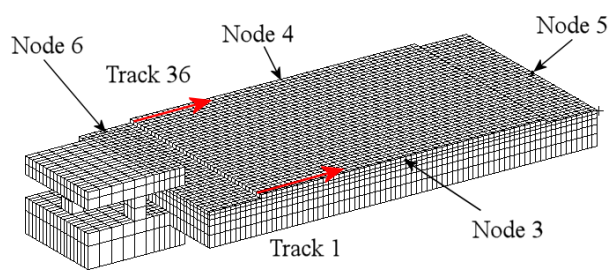

(a) Clad surface

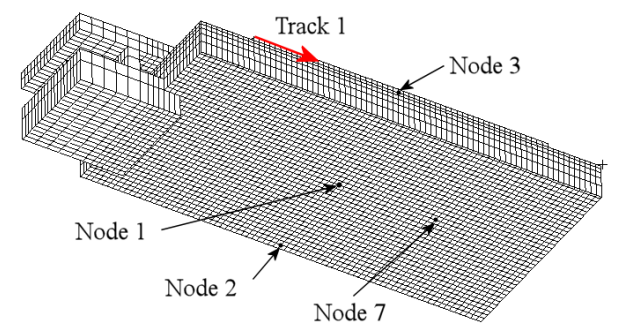

(b) Bottom surface

Figure 6: The finite element mesh of the substrate, clad, and the fixture's aluminum clamp. prescribe the laser heat source:

$$
Q=\frac{6 \sqrt{3} P \eta f}{a b c \pi \sqrt{\pi}} e^{-\left[\frac{3 x^{2}}{a^{2}}+\frac{3 y^{2}}{b^{2}}+\frac{3\left(z+v_{w} t\right)^{2}}{c^{2}}\right]}
$$


where $x, y$, and $z$ are local coordinates, $P$ is the laser power, and $\eta$ is the laser absorption efficiency. The laser power is known but the absorption efficiency is not, it is determined using inverse simulation, a process described in more detail by Denlinger et al. (2014). The variables $f, a, b$, and $c$ define the volume over which the heat source is distributed. The volume is defined such that the laser spot is circular with a radius equal to the laser radius and applied to a depth equal to the clad layer thickness. The heat source is not applied through the full depth of the melt pool because the far field effects investigated in this study were shown using preliminary simulations to be insensitive to the depth of the heat source model.

The argon jets emitted from the deposition head generate forced convection on the substrate and clad surfaces which must be incorporated into the FE analysis. Gouge et al. (2015) developed and validated a laser powder cladding 275 model which incorporated the measurements made by Heigel et al. (2015b) to account for the convection acting on the smooth substrate surface and rough powder clad surface, as shown in Figure 7. In this model, the convection acting on a smooth surface $\left(h_{\mathrm{smooth}}\right)$ is applied to the top surfaces of the substrate:

$$
h_{\text {smooth }}=75.3 \mathrm{e}^{-0.047 r}+33.7 \mathrm{~W} / \mathrm{m}^{2} /{ }^{\circ} \mathrm{C}
$$

while the convection acting on the rough surface $\left(h_{\text {rough }}\right)$ is applied to the powder clad surfaces:

$$
h_{\text {rough }}=69.0 \mathrm{e}^{-0.070 r}+21.7 \mathrm{~W} / \mathrm{m}^{2} /{ }^{\circ} \mathrm{C}
$$


where $r$ is the distance from the impingement point (laser center) in mm. A value of $9 \mathrm{~W} / \mathrm{m}^{2} /{ }^{\circ} \mathrm{C}$ is applied to all other surfaces. Because the wire clad surface is considerably smoother than the powder clad surface, as shown in Figure 4, the smooth convection model, Equation (12), is applied to both the substrate top surface and the clad surfaces when modeling the wire clad.

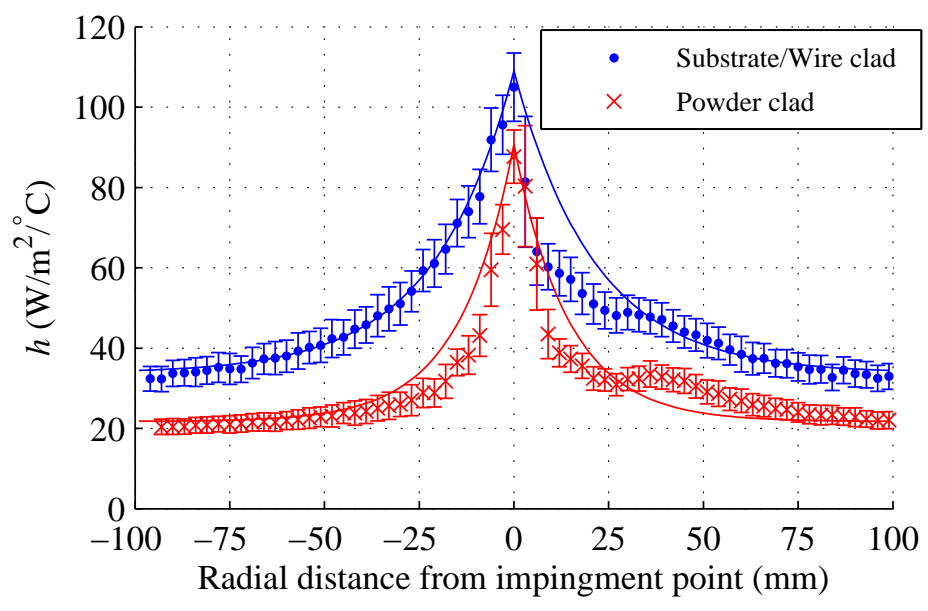

Figure 7: The convection measurements and the applied models.

CUBES $^{\circledR}$ (V2.38), a FE solver developed specifically for modeling additive manufacturing processes, is used to perform each analysis. Similar to laser cladding, additive manufacturing processes for metals use a high intensity heat source to melt the material to a substrate, enabling complex parts to be manufactured. The "quiet" element activation scheme is used such that all the elements in the deposition are included in the analysis but given material properties that minimize their impact on the analysis until they are activated. Thermal conductivity $(k)$, specific heat capacity $\left(C_{\mathrm{p}}\right)$, and elastic modulus $(E)$ of the "quiet" elements are scaled by factors of $10^{-6}, 10^{-2}$, and $10^{-4}$, 
respectively, before becoming active, at which point the scaling factors are removed and the temperature of those elements are re-set to ambient to prevent erroneous heating. Michaleris (2014) found that these scaling factors prevented the "quiet" elements from affecting the results and that resetting the element temperatures prevented erroneous heat input. The FE solver also re-assesses the 300 free surfaces of the part at each time increment, ensuring that convection and radiation are applied to all exposed free surfaces and not the internal surfaces.

\section{Results and Discussion}

\subsection{Temperature}

The measured temperature history resulting from the clad using each feedstock material is presented in Figure 8. The powder clad experiences higher temperatures at each location but the measured differences vary. The largest difference of approximately $100^{\circ} \mathrm{C}$ is measured on the bottom of the plate using TC 1 and TC 2, as well as on the side near the final pass using TC 4. However, the temperature difference between the two clads is less at the other locations. On the side nearest the first pass, the temperature difference is approximately $20^{\circ} \mathrm{C}$. The temperature difference further away from the clad area, measured on the front face using TC 5 and near the clamp using TC 6 , is approximately $50^{\circ} \mathrm{C}$. Although the temperature difference varies depending on the location on the plate, it is clear that the selection of powder feedstock results in higher 315 temperatures. 

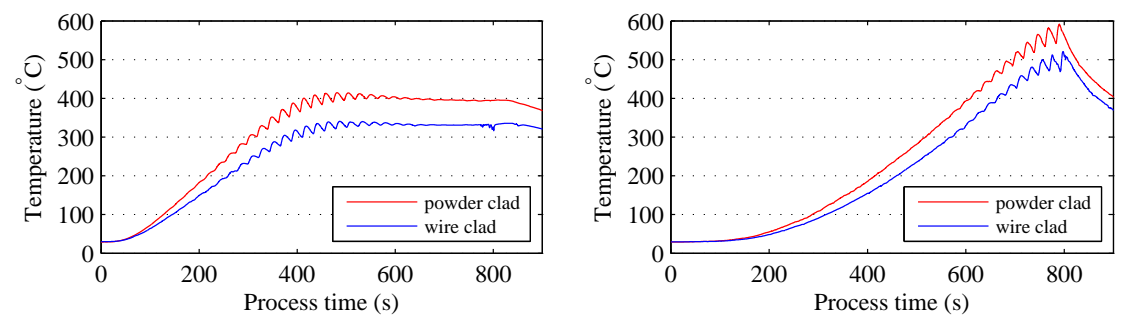

(a) TC 1, located on the center of the (b) TC 2, located on the bottom surface bottom surface. under the final passes.
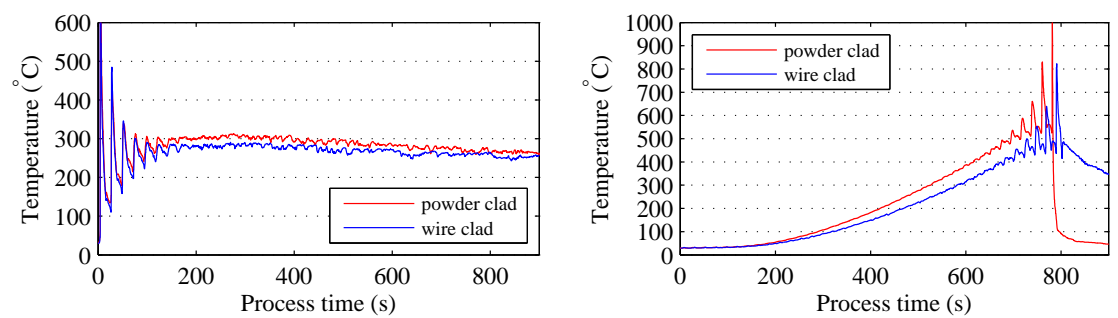

(c) TC 3, located on the side near the first (d) TC 4, located on the side near the last pass. pass.

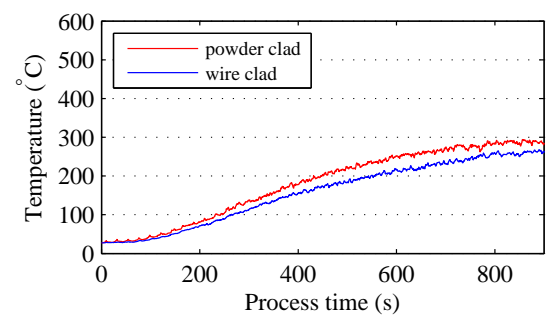

(e) TC 5, located on the front edge.

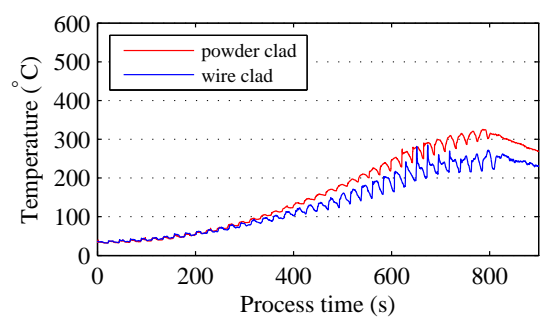

(f) TC 6, located near the clamp.

Figure 8: The temperature history measured by each thermocouple.

Because of the differences in measured temperatures despite the same nominal linear heat input, inverse simulation is used to estimate the laser absorption efficiency of each feedstock. Each plot in Figure 9 presents simulated thermal profiles using three different values of laser absorption efficiency $(\eta)$, and the measurements made by TC 1 (Figure 9). An absorption efficiency of $45 \%$ is found for the powder deposition, while $36 \%$ is found for the wire deposition. However, it should be noted that the $25 \%$ greater absorption of 
powder compared to wire in this current study is specific for these processing conditions. Although the powder can be heated by the laser mid-flight, thus increasing the net absorption, the powder stream in this application is focused at the part surface and therefore only briefly interacts with the beam before reaching the melt pool. Despite this limited in-flight interaction the powder still has the ability to increase the laser absorption efficiency. McVey et al. (2007) demonstrated that even pre-placed powder scatters the beam and increases the 330 net absorption in the powder.

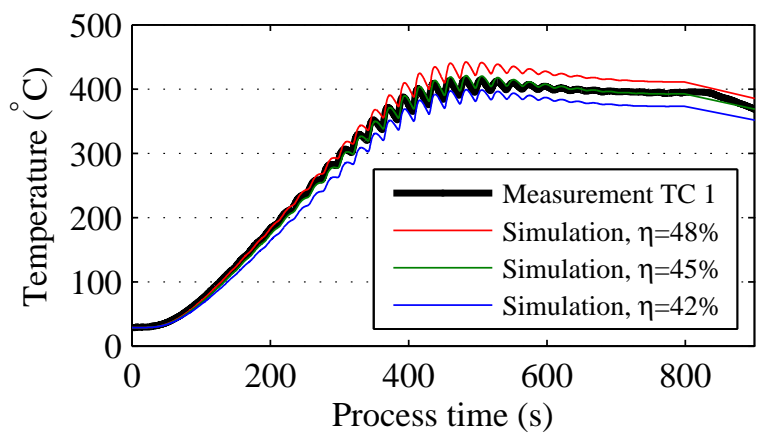

(a) Powder clad

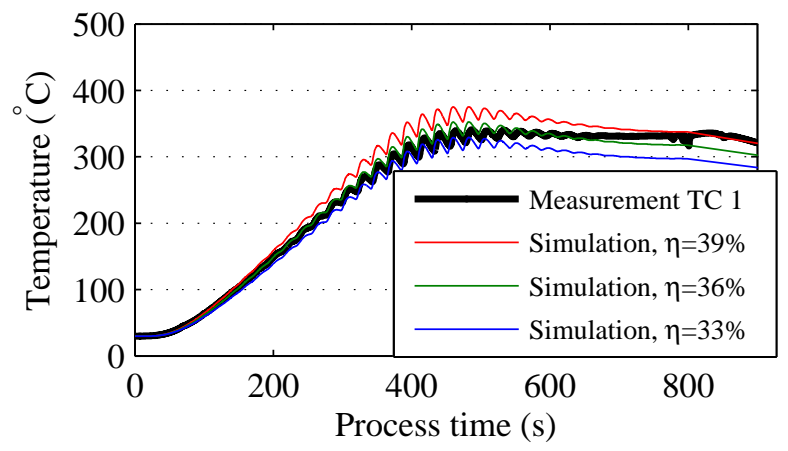

(b) Wire clad

Figure 9: The simulation results at Node 1 compared to TC 1 measurements for each case. 


\subsection{Melt pool dilution}

The images of the cross sections taken from each plate are shown in Figure 10. Each feedstock produces clads that are fully bonded with the substrate and free of voids. The ability of the powder to absorb energy from the laser beam in flight allows it to deposit a thicker clad than the wire $(1.42 \mathrm{~mm}$ compared to $0.74 \mathrm{~mm})$. Although the powder absorbs energy from the beam before it reaches the melt pool, a significant amount of energy is still able to reach the substrate to melt it. In fact, the melt pool in the powder clad is more than twice as deep as the melt pool that the wire is plunged into $(1.26 \mathrm{~mm}$ compared to

$0.56 \mathrm{~mm}$ ). The melt pool dilution of the powder clad is also greater according to Equation (3) (47\% compared to $43 \%$ for the wire). The thicker clad layer, deeper melt pool, and greater dilution of the powder clad are consequences of the higher laser absorption.

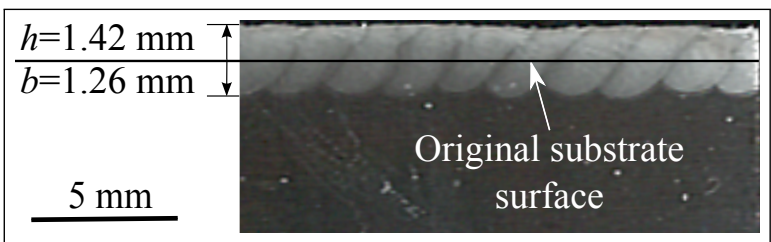

(a) Powder clad

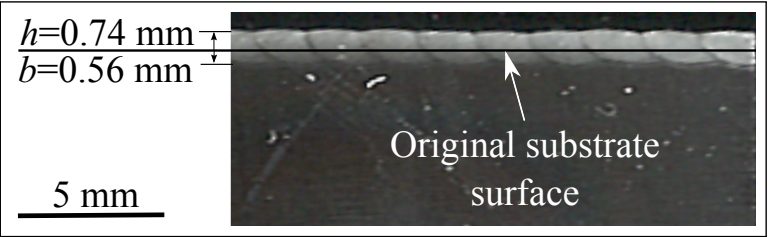

(b) Wire clad

Figure 10: Cross sections of each clad. The black horizontal line indicates where the original substrate surface. 


\subsection{Deflection}

The thermal cycling during the cladding process causes each plate to distort, as shown by the final shape of each plate, presented in Figure 11. Similar to the results presented by Heigel et al. (2015a), the data is rotated so results represent how the plate looked while clamped in the fixture. The location of each measurement point is shown using white dots while the location of the

350 LDS measurement is shown using a vertical line. Both the powder and wire feedstock cause the plates to deflect upward and to twist. The twist is defined according to

$$
\text { twist angle }=\operatorname{atan}\left(\frac{\text { CMM 1 }- \text { CMM 3 }}{63.50}\right)
$$

CMM 1 and CMM 2 are the measurements taken near the free end corners of the plate and $63.50 \mathrm{~mm}$ is the distance between these two measurements. Cladding 355 with the powder deposition generates $0.30^{\circ}$ of twist while the wire feedstock results in $0.32^{\circ}$. Although the wire feedstock generates $7 \%$ more twist than the powder, it produces $14 \%$ less distortion at the middle of the free end of the plate (4.70 mm compared to $5.49 \mathrm{~mm}$ at CMM 2). 


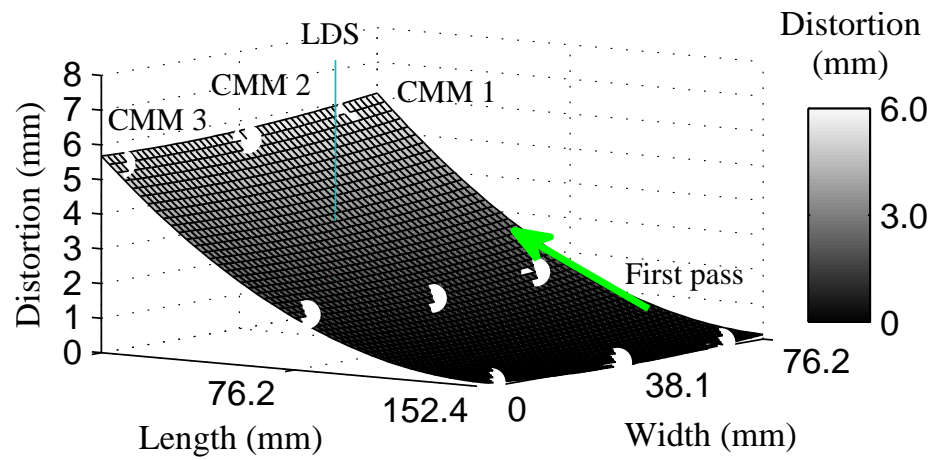

(a) Powder clad LDS

Distortion

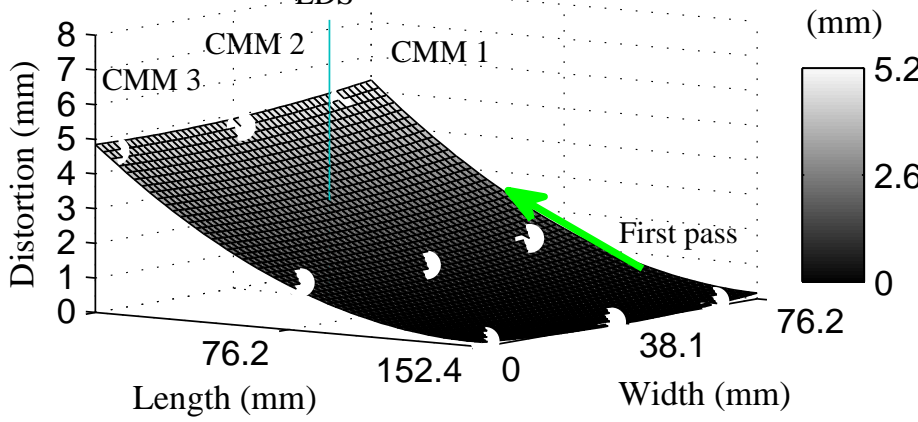

(b) Wire clad

Figure 11: The final distorted shape of each plate measured using a CMM.

The in situ deflection measurements presented in Figure 12 show how the distortion in each plate accumulates during the cladding process. The plate deflects downward in response to the thermal expansion of the material around a pass, then deflects upward as the material cools and contracts. A net increase in deflection occurs after each pass. At the LDS measurement location, the wire deposition concludes with $1.76 \mathrm{~mm}$ of deflection, while the powder deposition causes $2.15 \mathrm{~mm}$ of deflection, a difference of $0.39 \mathrm{~mm}$, or $22 \%$. Since the net increase in deflection from individual passes is similar, the average per-pass deflection is calculated by dividing the final deflection by the number of passes 
for each clad. For the powder clad, each pass causes the plate to deflect by 60 $\mu \mathrm{m}$ whereas each wire clad pass generates $48 \mu \mathrm{m}$ of deflection.

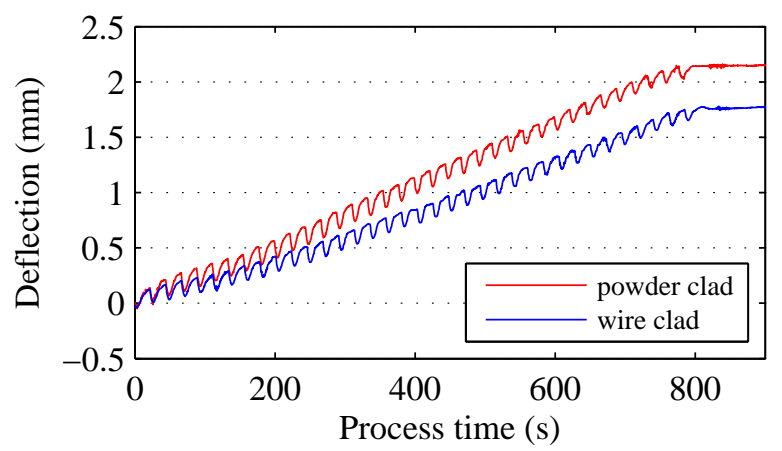

Figure 12: Deflection measurements.

The deflection trends and magnitudes are similar to an earlier study by Heigel et al. (2015a). For the same laser power, travel speed, hatch spacing, and mass feed rate of powder, the earlier study measured the deflection from individual passes to be $53 \mu \mathrm{m}$. The $12 \%$ difference in per-pass deflection in the earlier study and the powder results in this current work is likely attributed to differences in other processing considerations. For instance, the passes in the earlier study were $18 \mathrm{~mm}$ longer, the head was oriented perpendicular to the plate and not tilted $5^{\circ}$, and each pass started at the free end of the plate and not near the clamped end. All of these difference can impact processing time or the energy balance which were shown to affect the resulting plate distortion.

The mechanical simulation results of the deflection at Node 7 , which corresponds to the LDS measurement point, are presented in Figure 13. The deflection measurements are included to compare with the first layer simulation results. Because the wire clad thickness is half of the powder clad thickness, 
two layers of each are simulated so that the deflection resulting from similar 385 clad thickness can be compared. A 15 minute delay was imposed between the simulated layers, similar to the multi-layer clads performed by Heigel et al. (2015a).

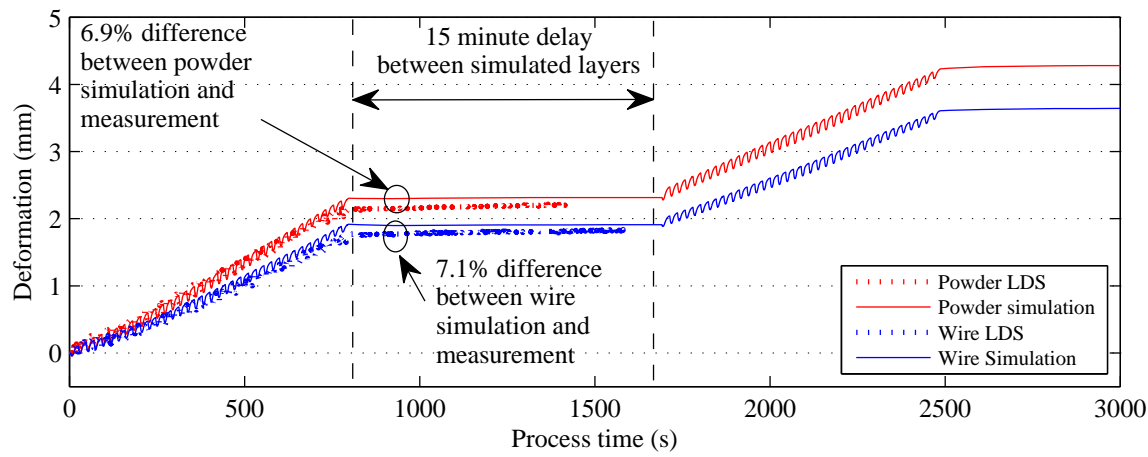

Figure 13: The simulation deformation results of two layers compared to the measurement of a single layer.

Good agreement is achieved between the measurements and the simulations of each feedstock. The deflection after the first layer in each case is slightly over-predicted when compared to the measurements. At approximately the $925 \mathrm{~s}$ mark, which is after the conclusion of the first layer, the simulation of the powder clad is $0.148 \mathrm{~mm}(6.9 \%)$ more than the measurement while the simulation of the wire clad is $0.126 \mathrm{~mm}(7.1 \%)$ greater than the measurement. Furthermore, the simulation of the second layer agrees well with the trends observed by Heigel et al. (2015a). Using a the same laser power $(2.5 \mathrm{~kW})$, travel speed $(10.6 \mathrm{~mm} / \mathrm{s})$, hatch spacing $(2.03 \mathrm{~mm})$, and powder feed rate $(19.0$ $\mathrm{g} / \mathrm{min})$, it was found that the second layer increased the total deflection by $78 \%$. Similarly, the simulation of the second powder clad layer increases the 
total deflection by $86 \%$, as shown in Figure 13 .

The simulation results are used to assess the deflection for similar clad thicknesses using either powder or wire. A single layer of the powder clad results in a thickness of $1.42 \mathrm{~mm}$ and a deflection of $2.28 \mathrm{~mm}$. Two layers of wire clad are required to achieve an approximately equal clad thickness of 1.48 mm. According to the simulation, the two layer wire clad will result in a total deflection of $3.61 \mathrm{~mm}$, which is significantly greater than the deflection caused by the single powder clad layer.

These results show that deflection is more dependent on the energy input into the part than on the layer thickness. If deflection is primarily dependent on the layer thickness, one would expect that doubling the layer thickness would double the resulting deflection. This is not the case since a single powder layer is 1.92 times thicker than an single wire layer, yet the measured deflection is only 1.22 times greater. Furthermore, while two wire layers would be expected to produce a net clad thickness that is only 1.04 times greater than the single powder layer, the simulated net deflection is actually 1.58 times greater. A ${ }_{415}$ better relationship is found by comparing the net energy absorbed by the part. For instance, the part absorbs $1.13 \mathrm{~kW}$ of energy from a single powder layer, $0.90 \mathrm{~kW}$ from a single wire layer, and a total of $1.80 \mathrm{~kW}$ from two wire layers. Considering single layers, the net energy absorbed during a single powder layer is 1.26 times greater than during a single wire layer and the resulting measured 420 deflection is 1.22 times greater. Comparing the single powder layer to two wire layers, the two wire layers result in 1.59 times the energy being input into the 
part while the net simulated deflection is 1.58 times greater. Therefore, the energy input into the part is a better predictor of the overall deflection.

\section{Conclusions}

The differences in the thermal and mechanical response of Inconel ${ }^{\circledR}$ 625 substrates laser clad with Inconel ${ }^{\circledR} 625$ powder and wire feedstock are investigated. The temperature and deflection histories of single layer clad processes are measured in situ, and the final distorted shape and melt pool dilution are measured post-process. A thermo-mechanical FE model is used to

${ }_{430}$ investigate the laser absorption efficiency of each feedstock and to simulate the deflection resulting from multi-layer cladding.

The results show that despite both processes utilizing the same laser power, travel speed, and hatch spacing, significant differences occur between laser cladding with powder or wire. For instance, analysis of the transverse cross 435 sections of each clad reveals that not only does the powder feedstock produce a thicker clad, it also results in more dilution compared to wire cladding. In addition, cladding with powder generates higher temperatures compared to those resulting from wire cladding. The FE model is used to demonstrate that the the powder feedstock enables a greater amount of laser energy to be absorbed

${ }_{440}$ (45\% compared to $36 \%$ ). Laser powder cladding of a single $1.42 \mathrm{~mm}$ thick layer causes the substrate to deflect more than laser wire cladding a single $0.78 \mathrm{~mm}$ thick layer, though the powder causes the plate to twist slightly less. However, FE simulation results of a second layer clad with wire reveal that in fact when 
each feedstock is used to clad a similar thickness, the wire generates $85 \%$ more

${ }_{445}$ deflection. Considering the results from this study, it is recommended that powder cladding be chosen over wire cladding when the surface appearance is not critical because it produces less distortion for a given clad thickness.

\section{Acknowledgments}

J.C. Heigel is supported by the National Science Foundation under Grant No. DGE1255832. The material is based upon work supported by the Office of Naval Research through the Naval Sea Systems Command under Contract No. N0002402-D-6604, Delivery order No. 0611. Any opinions, findings, and conclusions or recommendations expressed in this material are those of the authors and do not necessarily reflect the views of the National Science Foundation or the Office of 455 Naval Research.

\section{References}

Denlinger, E., Heigel, J., and Michaleris, P. (2014). Residual stress and distortion modeling of electron beam direct manufacturing Ti-6Al-4V. Proc. Inst. Mech. Eng., B J. Eng. Manuf., pages 1-11.

${ }_{460}$ Denlinger, E., Irwin, J., and Michaleris, P. (2015). Thermo-mechanical modeling of additive manufacturing large parts. J. Manuf. Sci. E.-T. ASME, 136(6).

Goldak, J., Chakravarti, A., and Bibby, M. (1984). A new finite element model for welding heat sources. Metall. Trans. B, 15(2):299-305. 
Gouge, M., Heigel, J., Michaleris, P., and Palmer, T. (2015). Modeling forced 465 convection in the thermal simulation of laser cladding processes. Int. J. Adv. Manuf. Technol., 79(1):307-320.

Grum, J. and Žnidaršič, M. (2004). Microstructure, microhardness, and residual stress analysis of laser surface cladding of low-carbon steel. Mater. Manuf. Process., 19(2):243-258.

470 Heigel, J., Michaleris, P., and Palmer, T. (2015a). In-situ monitoring and characterization of distortion during laser cladding of a nickel base alloy. In press. J. Mater. Proces. Tech., 220:135-145.

Heigel, J., Michaleris, P., and Palmer, T. (2015b). Measurement of forced surface convection in directed energy deposition additive manufacturing. Proc. Inst. Mech. Eng., B J. Eng. Manuf.

Heigel, J., Michaleris, P., and Reutzel, E. (2014). Thermo-mechanical model development and validation of directed energy deposition additive manufacturing of Ti-6Al-4V. Add. Man.

Huang, Y., Liang, G., Su, J., and Li, J. (2005). Interaction between laser beam 480 and powder stream in the process of laser cladding with powder feeding. Modelling Simul. Mater. Sci. Eng., 13:47-56.

Keicher, D., Smugeresky, J., Romero, J., Griffith, M., and Harwell, L. (1997). Using the laser engineered net shaping (LENS) process to produce complex components from a CAD solid model. In Photonics West'97, pages 91-97. International Society for Optics and Photonics. 
Kim, J.-D. and Peng, Y. (2000a). Melt pool shape and dilution of laser cladding with wire feeding. J. Mater. Proces. Tech., 104(3):284-293.

Kim, J.-D. and Peng, Y. (2000b). Plunging method for Nd: YAG laser cladding with wire feeding. Opt. Laser Eng., 33(4):299-309.

490 Lawrence, A. and Michaleris, P. (2011). Effects of thermal transport in computation of welding residual stress and distortion. Sci. Technol. Weld. Joi., 16:215-220.

Lin, J. (1999). Temperature analysis of the powder streams in coaxial laser cladding. Opt. Laser Tech., 31(8):565-570.

495 McVey, R., Melnychuk, R., Todd, J., and Martukanitz, R. (2007). Absorption of laser irradiation in a porous powder layer. J. Laser Appl., 19:214.

Metals, S. (2006). Inconel alloy 625. Technical Report Publication Number SMC-063.

Michaleris, P. (2014). Modeling metal deposition in heat transfer analysis of additive manufacturing processes. Finite Elem. Anal. Des., 86:51-60.

Ocelík, V., Bosgra, J., and de Hosson, J. (2009). In-situ strain observation in high power laser cladding. Surf. Coat. Tech., 203(20):3189-3196.

Omega Engineering Inc. (1998). Non-contact temperature measurement vol 1 2nd ed. Technical Report Transactions Vol 1.

Partes, K. (2009). Analytical model of the catchment efficiency in high speed laser cladding. Surf. Coat. Tech., 204(3):366-371. 
Plati, A., Tan, J., Golosnoy, I., Persoons, R., Van Acker, K., and Clyne, T. (2006). Residual stress generation during laser cladding of steel with a particulate metal matrix composite. Adv. Eng. Mat., 8(7):619-624.

Toyserkani, E., Khajepour, A., and Corbin, S. (2003). Three-dimensional finite element modeling of laser cladding by powder injection: effects of powder feedrate and travel speed on the process. J. Laser Appl., 15(3):153-160.

Toyserkani, E., Khajepour, A., and Corbin, S., editors (2005). Laser Cladding. CRC Press. 